Journal of Management and Social Science Research, 1(1/2), 34-42, 2020

ISSN: 2735-9395 (Print) 2735-9360 (Online) Available online at credencepressitd.com, DOI 10.47524/jmssr.11.5

\title{
Materials management and productivity of fast moving consumer goods companies in Nigeria: A canonical correlation approach
}

\author{
Egberi A. Kelvin B.Sc., M.Sc., PhD \\ Department of Business Administration and Management \\ School of Business Studies \\ Delta State Polytechnic, Ozoro Delta State, Nigeria \\ Okorie Chiyem B.Sc., M.Sc. \\ Department of Marketing \\ School of Business Studies \\ Delta State Polytechnic, Ozoro Delta State, Nigeria \\ Email: chiyemokorie.edu@gmail.com
}

\begin{abstract}
In this paper, the effect of material management on productivity level of fast moving consumer products enterprises in Nigeria was assessed. The survey design was employed and questionnaire was the major instrument of data collection designed via two material management dimensions (raw materials and work-inprogress) and productivity dimensions (material efficiency and yield). Questionnaire were administered to three hundred and seven (307) respondents and data obtained were analyzed using Canonical correlation. Results of canonical correlation analysis revealed that the combination of material efficiency and yield (productivity proxies) had a statistically significant relationship on sets of material management being measured by raw material and work-in-progress. The study concludes that improvement in material management will increase the productivity of FMCG companies in Nigeria. Given the results of the study, improvements in material management is needed such that material requisition and conversion units should ensure that required materials for production of goods are those put into the production process in order to realize efficiency of production and superior yield of finished goods by fast moving consumer products organizations. In addition, fast moving products companies should ensure maintenance of optimum level of material resources in its store room and reduce unhealthy practice in material usage that are pivotal to reducing productivity.
\end{abstract}

Keywords: Material management; Organizational productivity; Material efficiency; Material yield; Raw material; Fast moving consumer goods companies

JEL Classification: J24; M11; M9

\section{Introduction}

In the past, materials management was traced as a cost-centre because purchasing department spent money on material whereas store held enormous material inventories, blocking space and money (Ramakrishna, 2005; JerutoKeitany, Wanyoike\&Richu, 2014). Nevertheless, with the advent of globalization and expansion in information technology (IT), a drastic change occurred in the business environment such that organizations are opened to stern competition in marketplace (Oba, Ayoola,Ademola\&Obadeji, 2017; Dagim, 2018; Garba, 2020); thus the need to utilize material resources for effective productivity. Sturkhart (2007) asserts that total cost of materials may be 60 percent or more; however, in most cases, cost of materials may exceed 50 percent of total cost of goods. Consequently, large investments in material resources demand effective control and planning in order to minimize material waste, which unvaryingly affect companies' productivity (Ondiek\&Odera, 2012).

Song, Haas and Caldas (2006); Cross (2019); Kisioya and Moronge (2019); Oteki and Sakwa (2020) opined that 
Egberi A. Kelvin and Okorie Chiyem: Materials management and productivity of fast moving consumer goods companies in Nigeria: A canonical correlation approach

companies engaging in efficient material management are most probable to perform better than those that do not and realize significant savings in total costs of production; hence, effective materials management can result to cost reduction, savings and overall, productivity. According to Banjoko (2009), the diverse forms of materials needed to be managed encompassed raw materials, work-inprogress (WIP) and finished goods. Impliedly, materials management refers to the management of raw materials, WIP and finished goods in order to reduce costs linked with production.

Prior researches (Ondiek, 2009; Asaolu, Agorzie\&Unam, 2012; Dagim, 2018; Cross, 2019; Kisioya\&Moronge, 2019; Muchaendepi, Mbohwa, Hamandishe\&Kanyepe, 2019; Nyongesa\& Shale, 2019; Oteki\&Sakwa, 2020; Garba, 2020) have shown that materials management accounts more than annual turnover of companies. This suggests that precedence should be given to materials management in fast moving consumer goods companies in order to avert excessive production costs. Given that fast moving consumer goods companies experience material waste in the course of production, there is therefore the need for fast moving consumer goods companies to have improved ways and strategies of managing material resources in order to reduce wastage in value chain and thus augmenting productivity.

Unfortunately, there are scanty empirical evidences on materials management and productivity, particularly of Fast Moving Consumer Goods (FMCG) companies in Nigeria. This study therefore was carried out with the view to assessing the effect of materials management (using material management components - raw and work-in-progress materials) on organizational productivity dimensions (material efficiency and yield) of FMCG companies in Nigeria. The raw material and work-in-progress are material inputs while material efficiency and yield are materials output measures.

\section{Theoretical literature and conceptual model}

In literature, materials management has been widely recognized as a vital tool for boosting the productivity of organizations since it curtails costs and makes the best use of existing resources.

Cross (2019) opines that materials management offers an integral methods of proper planning of materials activities and total material price. Ogbadu (2009) asserts that organizations can retain adequate materials inventories in diverse forms to ensure profit. In this regard, material inventories may serve as a link between production and consumption of goods in organizational settings (Oba, et al 2017; Dagim, 2018).

In recent times, organizations invest huge resources in materials management in order to curtail material wastage (Ondiek\&Odera, 2012), cost saving (Song, Haas \& Caldas, 2006; Cross, 2019) and enhanced productivity (Banjoko, 2009; Asaolu, et al, 2012). Management literature suggests that materials management accounts more than yearly turnover organizations record (Cross, 2019; Ondiek, 2009), and as such materials management is considered a dynamic strategy for enhancing turnover, performance and productivity.

Barker (1989); Linton, Klassen and Jayaraman (2007) acknowledged five main functional areas of materials management to include purchasing, inventory and quality controls, warehousing/ storage, distribution and production (raw materials conversion to work-in-progress and finished goods).Materials management refer to purchasing, warehousing and controlling of organization materials in an optimum manner such that a predetermined service to customers at a lowest cost can be realized (Ramakrishna, 2005; Gopalakrishnan \& Sundaresan, 2006). 
Egberi A. Kelvin and Okorie Chiyem: Materials management and productivity of fast moving consumer goods companies in Nigeria: A canonical correlation approach

Banjoko (2009) asserts that for organizations to enhance productivity, it must consider materials management as the lifeblood of the production process. This means that organizations materials for production must be available at a suitable price, quantity, quality and be able to coordinate and schedule production activity. In materials management literature, there are two key issues organizations avoid - under-stock and overstock in order to enhance productivity (Navon\&Berkovich, 2006). According to Jacobs, Chase and Aquilano (2009); JerutoKeitany, et al (2014), the fundamental objective of materials management is aimed at purchasing the right items and making them available to production unit at the right time, and possible lowest cost.

Materials management according to Levi, et al (2009) have a vital influence on organization's performance and productivity. Prior researches (Ondiek\&Odera, 2012; Asaolu, et al 2012; JerutoKeitany, et al 2014; Oba, et al, 2017; Dagim, 2018; Cross, 2019) found that materials management have significant effect on organizational productivity and that the effect emanates in form of efficiency and better yields in production processes. More worrisome is the fact that there have been no empirical studies in developing countries like Nigeria with abundant Fast Moving Consumer Goods companies desirous of improved materials management strategies in order to breakeven or enhance productivity.

Notwithstanding the objectives of materials management, Banjoko (2009) posits that the types of materials to be managed by organizations embraced purchased raw materials, work-in-progress and finished goods. This study was carried out with the view to assessing the effect of materials management (using material management components - raw and workin-progress materials) on organizational productivity dimensions (material efficiency and yield) in Nigeria. In view of the theoretical literature, the following conceptual model was developed to guide the canonical model:

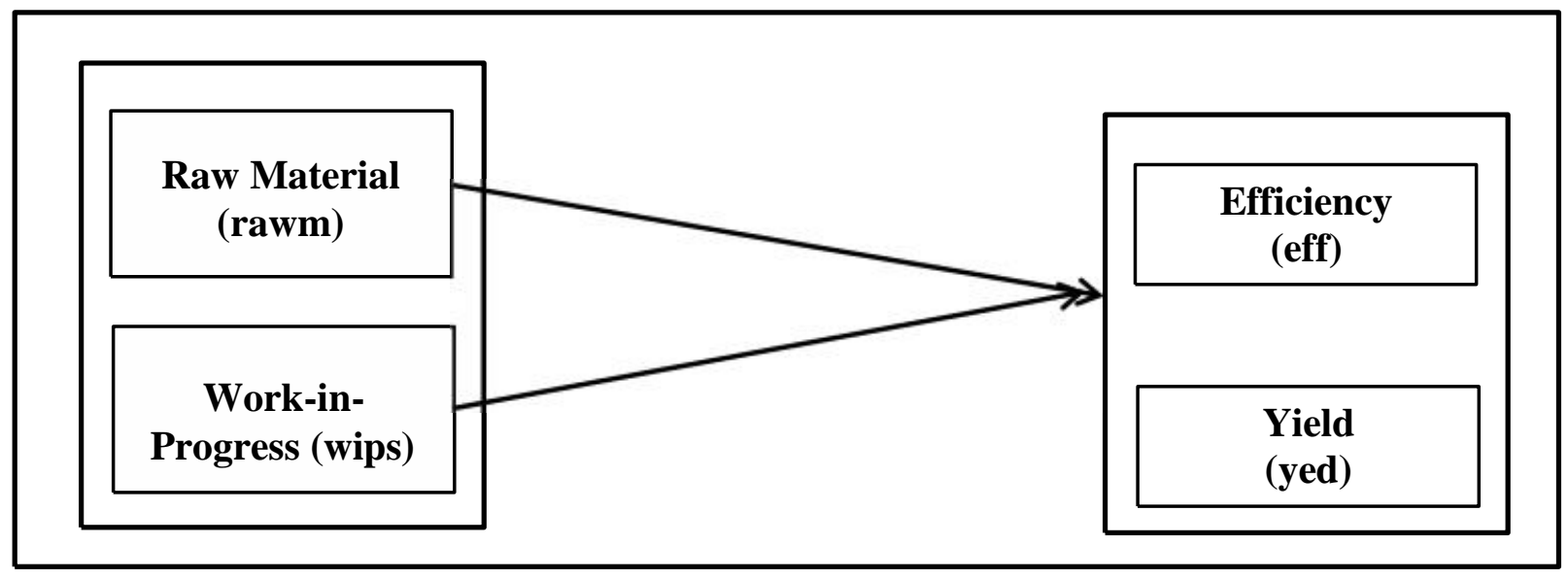

Fig. 1: Conceptual model of the study

Source: Conceptualized by the researcher, 2020

\section{Research methods}

This paper adopts descriptive survey research design in order to assess the relationship between materials management and productivity dimensions of Fast Moving Consumer Goods (FMCG) companies in Nigeria. The survey design was employed since the study seeks to obtain the viewpoints of people on the research subject.

A sample of three hundred and seven (307) respondents were randomly selected from two viable FMCG companies - Nestle

Journal of Management and Social Science Research, Volume 1, Numbers 1/2, 2020 
Egberi A. Kelvin and Okorie Chiyem: Materials management and productivity of fast moving consumer goods companies in Nigeria: A canonical correlation approach

Nigeria and Nigerian Brewery and a 20itemed questionnaires were administered to employees of the studied FMCG companies who are the participants of the study; the study sample was obtained via convenience sampling technique. The 5-point Likert type scale instrument was used as basis for questionnaire design and a pilot test was carried out; questionnaire was adjusted to the present form in which it was used to obtain data for the study.

The questionnaire was designed in two parts (Parts I - bio-data of respondents \& II - thematic issues); questionnaire items in Part II captured materials management dimensions (raw material and work-inprogress) and productivity dimensions (materials efficiency and yield). Part II of the questionnaire recorded a Cronbach Alpha reliability coefficient of 0.75 , which according to Manson, Lind and Marchal (1999) is considered a reliable instrument since it is not less than 0.5. The data obtained from the survey was illustrated using descriptive statistics like pictorial charts, mean, median, standard deviation, kurtosis, and skewness while inferential (Canonical correlation) statistical technique was employed in analyzing data obtained in the field survey.

Canonical correlation approach has the ability to handle multiple sets of dependent variables and independent variables (Hotelling, 1936; Thompson, 1999; Fan, 1997; Sherry \&Hensen, 2005), hence was adopted as analytical framework. The model specification examines the relationship between sets of material management and productivity dimensions as stated thus:

eff $=f$ (rawm, wips $) \quad-\quad$ eq. 1

yed $=f$ (rawm, wips $) \quad-\quad$ eq. 2

Where: Productivity was measured by materials efficiency (eff) and yield (yed) while materials management was proxied by raw material ( $\mathrm{rawm})$ and work-in-progress (wips).

eff $=\beta_{0}+\beta_{1 \text { rawm }}+\beta_{2}$ wips $+\mu_{t}-\quad$ eq. 3 yed $=\beta 0+\beta$ 1rawm $+\beta_{2}$ wips $+\mu_{t}-\quad$ eq. 4 Questionnaire items were raised on the dependent variables dimensions (productivity- materials efficiency and yield) and the independent variables dimensions (materials management - raw material and work-in-progress). The statistical analysis was carried via STATA 13.0 software.

\section{Results and discussions}

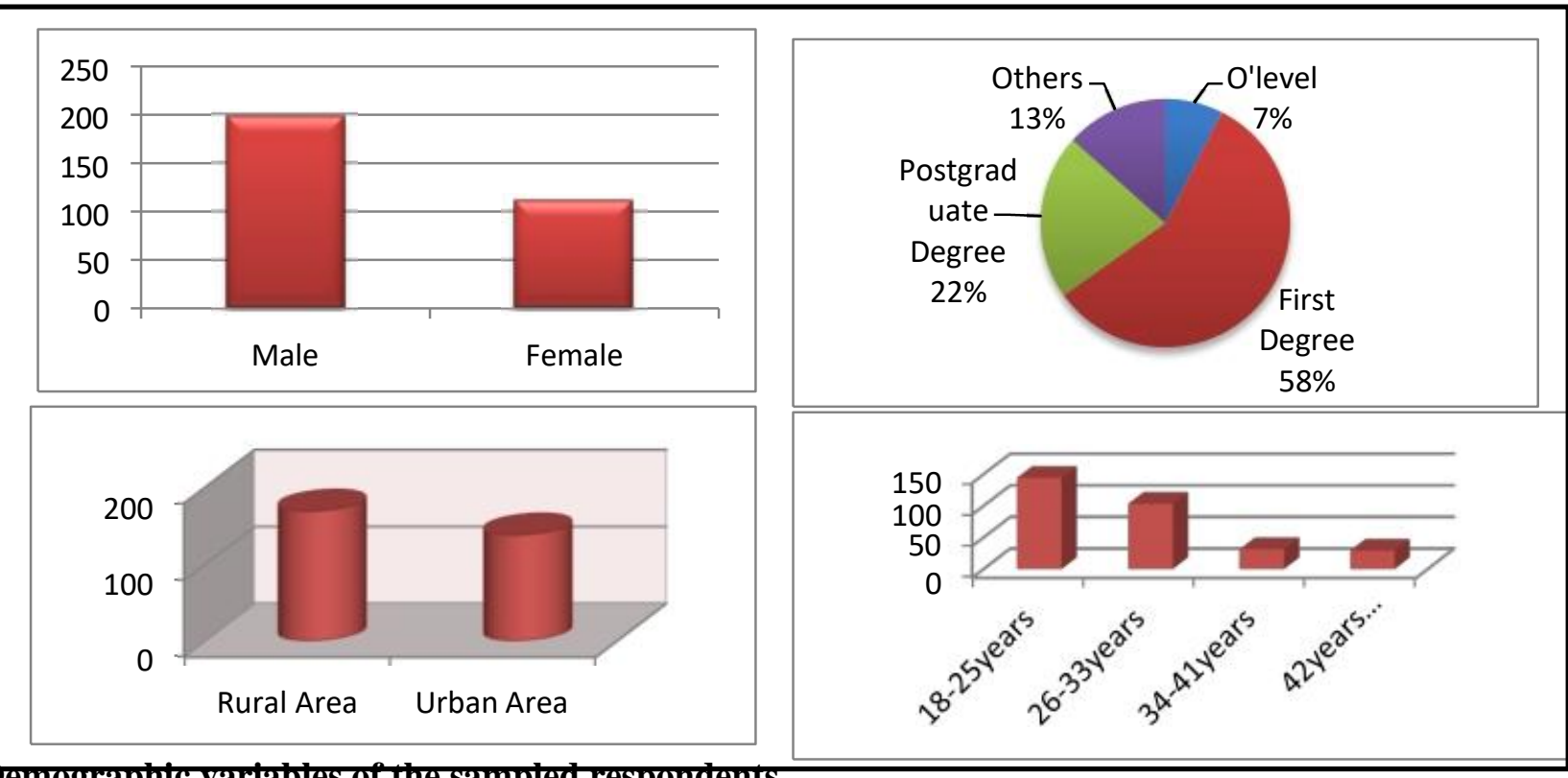

Fig. 2: Demograptitc vartatotes of the sampled respondents

Figure 2 shows the demographic variables of 307 sampled respondents; the results reveal that the respondents cut across diverse genders, educational qualification, area of resident and age group, which gives the study 
Egberi A. Kelvin and Okorie Chiyem: Materials management and productivity of fast moving consumer goods companies in Nigeria: A canonical correlation approach

a broader assessment of the viewpoints of diverse respondents on the research theme.

Table 1: Descriptive statistics

\begin{tabular}{lllll}
\cline { 5 - 5 } Statistics & Eff & yed & Rawm & Wips \\
\hline Mean & 4.4848 & 4.6118 & 4.3649 & 3.6395 \\
Median & 4.6126 & 4.6126 & 4.3243 & 3.6057 \\
Std. dev. & 0.5803 & 0.6107 & 0.5109 & 0.4260 \\
Minimum & 1 & 1 & 1 & 1.0000 \\
Maximum & 5 & 5 & 5 & 4.0000 \\
Skewness & -0.8459 & 4.7972 & 4.7972 & -0.6351 \\
Kurtosis & 3.9798 & -0.9417 & -0.7617 & 3.6260 \\
Sum & 1466.5 & 1507.9 & 1427.3 & 1501.7 \\
Observation & 307 & 307 & 307 & 307 \\
\hline
\end{tabular}

Source: Computed by Researcher, 2020

Presented in Table 1 is the descriptive result of dependent (eff and yed) and independent (rawm and wips) variables of study. The results showed that all variables beat the mean threshold of 2.00, suggesting that respondents perceived questionnaire items as fundamental dimensions of material management and organizational productivity. In addition, dependent and independent variables moved in similar direction as shown in skewness(negative signs). Also, the dependent and independent variables are normally distributed since kurtoses are closer to 3 .

The correlation matrix obtained using canonical model have provision in assessing the separate correlation matrix on sets of dependent, independent and combination of both variables as shown in Tables $2 \mathrm{a}, 2 \mathrm{~b}$ and $2 \mathrm{c}$. The preliminary test of correlation matrix is vital since there is need to establish whether the data is free from multi-collinearity problem; results are presented in Tables 3-5:

Table 2: Correlation matrix for productivity

\begin{tabular}{lll}
\cline { 2 - 3 } & eff & Yed \\
\hline Eff & 1.0000 & \\
Yed & -0.1187 & 1.0000 \\
\hline
\end{tabular}

Source: Computed by Researcher, 2020

Table 3: Correlation matrix for materials management

\begin{tabular}{lll} 
& Rawm & wips \\
\hline Rawm & 1.0000 & \\
Wips & 0.1410 & 1.0000 \\
\hline
\end{tabular}

Source: Computed by Researcher, 2020

Table 4: Correlation matrix between materials Management and Productivity Dimensions

\begin{tabular}{lll}
\cline { 2 - 3 } & Eff & Yed \\
\hline Rawm & 0.0735 & -0.0275 \\
Wips & -0.0946 & 0.0404 \\
\hline
\end{tabular}

Source: Computed by Researcher, 2020

Using rule of thumb, the results shown in Tables 2, 3 and 4 suggest the absence of multi-collinearity as none of the correlation coefficients is above -0.70 and

Journal of Management and Social Science Research, Volume 1, Numbers 1/2, 2020 
Egberi A. Kelvin and Okorie Chiyem: Materials management and productivity of fast moving consumer goods companies in Nigeria: A canonical correlation approach

0.70 benchmark (Manson, Lin \& Marshall, 1999).

Table 5: Raw coefficients (first and second variable sets)

Raw coefficients for the first variable set

\begin{tabular}{lll}
\cline { 3 - 3 } & $\mathbf{1}$ & $\mathbf{2}$ \\
\hline Eff & 0.0349 & -0.0956 \\
Yed & 0.0002 & 0.0013 \\
\hline
\end{tabular}

Source: Computed by Researcher, 2020

Raw coefficients for the second variable set

\begin{tabular}{lll}
\hline & $\mathbf{1}$ & $\mathbf{2}$ \\
\cline { 2 - 4 } Rawm & 0.0908 & -0.3572 \\
Wips & -0.0300 & 0.0425 \\
\hline
\end{tabular}

Source: Computed by Researcher, 2020

Table 5 reveals that one-unit increase in raw material (rawm) of raw coefficient for the second variable set leads to 0.0908 increases in the first canonical variate ' $\mathrm{V}$ ' when all other variables are held constant. Besides, the association between material management and productivity sets of variables are weak.

Table 3b: Summary of CCA result for test of overall hypothesis

\section{Canonical correlations:}

0.24260 .10070 .0380

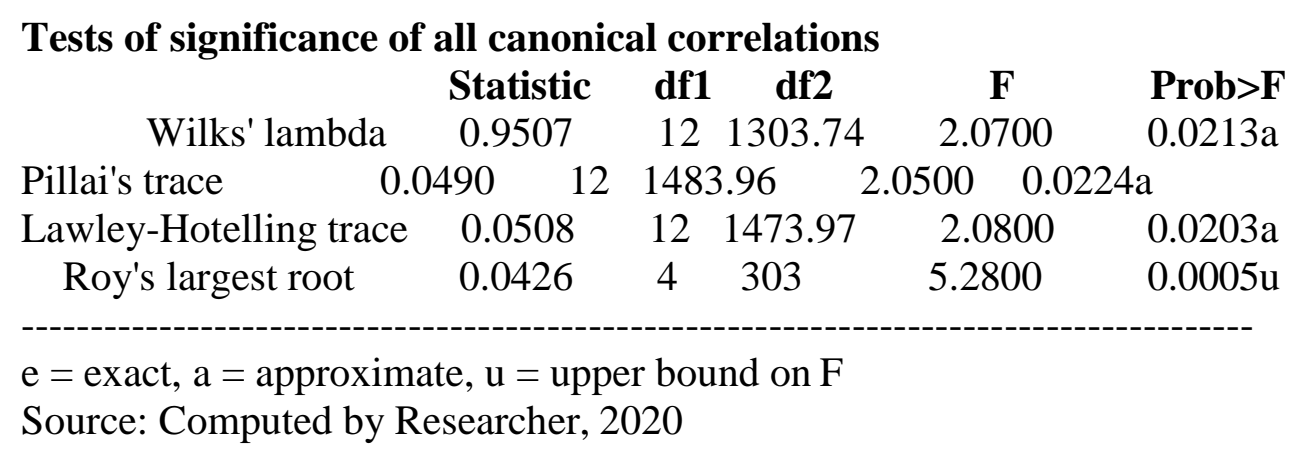

The first test to confirm the null hypothesis that there is no significant relationship between set of material management and productivity is the Wilks'Lambda test statistic with a value of $09507, \mathrm{~F}$-value of 2.0700 and the $\mathrm{P}$-value of 0.0213 which is less than 0.05.Therefore, the null hypothesis is rejected, and alternate hypothesis which states that there is significant relationship between the sets of material management variables and all sets of productivity variables is accepted. Besides, the second test, Pillai's trace result showed a value of 0.0490 , with $F$ value of 2.0500 and $\mathrm{P}$-value of 0.0224 , while Lawley-Hotelling trace statistic reported 0.0508 and F-value of 2.0800 with P-value of 0.0203 . Both test results are less than $5 \%$ level of significant. Finally, the fourth test, Roy's largest root results also reported a statistics value of $0.0426, \mathrm{~F}$-value of 5.2800 and P-value of 0.0005 , indicating $1 \%$ level significance between sets of material management and sets of productivity.

Summarily, test of significance of all canonical correlations indicates that the null hypotheses is rejected and the study can clearly conclude that a significant association exists between the sets of 
Egberi A. Kelvin and Okorie Chiyem: Materials management and productivity of fast moving consumer goods companies in Nigeria: A canonical correlation approach

productivity measurements and that of material management using Wilks'Lambda, Pillai's trace and Lawley-Hotelling trace at $5 \%$ level of significance and $1 \%$ level of significance for Roy's largest root. This finding collaborates the results of Ondiek and Odera (2012); Asaolu, Agorzie and Unam (2012); JerutoKeitany, Wanyoike and Richu (2014); Oba, Ayoola,Ademola\&Obadeji (2017); Dagim and (2018); Cross (2019); Oteki and Sakwa (2020); Garba (2020) that material management have significant effect on organizational productivity and that the effect results efficiency and better yields in the production processes of organizations.

\section{Conclusions and recommendations}

This paper assessed the effects of material management on productivity level of FMCG companies in Nigeria. Questionnaire was the major instrument of data collection designed via two material management dimensions (raw materials and work-in-progress) and productivity dimensions (material efficiency and yield). Data obtained in the field survey were portrayed using descriptive statistics while inferential (Canonical correlation) statistical tool was used in validating whether material management significantly affect productivity level of FMCG in Nigeria.

Overall, the results of canonical correlation analysis revealed that the combination of material efficiency and yield (proxy for productivity) had a statistically significant relationship on the sets of material management being measured by raw material and work-inprogress; more so, the relationship between material management and productivity level of FMCG is weak. More importantly, the study concludes that improvement in material management will increase the productivity of FMCG companies in Nigeria. The weak correlation suggests that FMCGs have not been able to manage materials in their productive processes effectively and efficiently.

On the basis of the foregoing analysis, the study suggests improvement in material management such that material requisition and conversion units should ensure that the required materials for production of goods are those put into the production process in order to realize efficiency of production and superior yield of products by fast moving consumer goods (FMCG) companies. More so, FMCG companies should ensure maintenance of optimum level of material resources in its store room and reduce unhealthy practice in material usage that are pivotal to reducing productivity. In fact, FMCG companies should adopt information technology as a major part of its inventory control systems; this would guarantee improved productivity.

\section{References}

Asaolu, T.O., Agorzie, C.J. \&Unam, J.M. (2012). Materials management: An effective tool for optimizing profitability in Nigerian food and beverage manufacturing industry. Journal of Emerging Trends in Economics and Management Sciences, 3(1), 25-31

Banjoko, S. A. (2009). Production and operations management. Lagos: Saban Publishers.

Barker, T. (1989).Essentials of materials management.London: McGraw Hill Book Company

Cross, O.D. (2019). Effects of materials management on the productivity of an organisation.World Journal of Innovative Research, 6(1), 16-22

Dagim, W. (2018). The role of material management

on organizationalperformance: A case study in commercial bank of Ethiopia. Industrial Engineering Letters, 8(4), 57-63

Fan, X. (1997). Canonical correlation analysis and structural equation modeling: What do they have in 
Egberi A. Kelvin and Okorie Chiyem: Materials management and productivity of fast moving consumer goods companies in Nigeria: A canonical correlation approach

common? Structural Equation Modeling, 4(1), 65-79.

Garba, A. (2020). Effect of material management on the performance of Benue brewery industry, Nigeria.International Journal of Research Granthaalayah, 8(2), 228-234

Gopalakrishnan, P. \&Sundaresan, M. (2006).Materials management: An integrated approach, New Delhi: Prentice Hall.

Hotelling, H. (1936). Relations between two sets of variates.Biometrika, 28, 321-377. doi:10: 2307/233955.

Jacobs, R.F. Chase, R.B., \&Aquilano, N.J. (2009).Operations and supply management. Boston: Mc-Graw Hill.

JerutoKeitany, P., Wanyoike, D.M. \&Richu, S. (2014). Assessment of the role of materials management on organizational performance: A case of new Kenya cooperative creameries limited. European Centre for Research Training and Development, 1(1), 1-10

Kisioya, D.K. \&Moronge, M. (2019). Influence of material handling practices on performance of firms in Nairobi county, Kenya. The Strategic Journal of Business and Change Management, 6(4), 745760

Levi D.S., Kaminsky P., Levi E.S. \& Shankar R. (2009).Designing and managing the supplychain: Concepts, strategies and case studies, 3rded. New Delhi: Tata McGraw Hills

Linton, J.D. Klassen, R. \&Jayaraman, V. (2007). Sustainable supply chains: An introduction. Journal of Operations Management, 25(6), 1075-1082.

Manson, R.D., Lind, D.A., \&Marchal, W.G. (1999).Statistical techniques in business and economics, 10thed. New York: Irwin McGraw-Hill.
Muchaendepi, W., Mbohwa, C., Hamandishe, T. \&Kanyepe, J. (2019).Inventory management and performance of manufacturing sector of Harare.Procedia Manufacturing, 33(2019), 454-461

Navon, R. \&Berkovich, O. (2006).An automated model for materials management and Control.Construction Management and Economics,24(6), 635-646.

Nyongesa, J.K. \& Shale, N. (2019). Influence of material management on performance of large manufacturing firms in Nairobi city county, Kenya. International Journal of Social Science and Information Technology, 5(5), 4862

Oba, A.D., Ayoola, Q.A., Ademola, A. \&Obadeji, J. (2017).The effectiveness procurement on material management in manufacturing industries.International Journal of Advanced Scientific Research, 2(2), 1-12

Ondiek, G.O. \&Odera, O. (2012).Assessment of materials management in Kenyan manufacturing firms.Journal of Business Studies Quarterly, 3(3), 40-49

Ondiek, G.O. (2009). Assessment of materials management in the Kenyan manufacturingfirms. Exploratory survey of manufacturing firms based in Nairobi. Journal of SocialSciences, 22(8), 88-110.

Oteki, E.B. \&Sakwa, M. (2020).Electronic material management practice on supply chain performance of sugar processing firms in Kenya.International Journal of Managing Value and Supply Chains, 11(2) 1-15

Ramakrishna, R.V. (2005). Materials management-profit centre. Indian 
Egberi A. Kelvin and Okorie Chiyem: Materials management and productivity of fast moving consumer goods companies in Nigeria: A canonical correlation approach

Institute of Materials Management Journal, 8(6)75-83.

Sherry, A. \&Hensen, R.K (2005). Conducting and interpreting canonical correlation analysis in personality research: A userfriendly primer. Journal of Personality Assessment, 84, 37-48.

Song, J., Haas, C.T., \& Caldas, C.H. (2006).Tracking the location of materials on constructionjob sites.Journal of Construction
Engineering and Management, 132(9), 911-918.

Stukhart, G. (2007). Materials management approach for small scale sector. New York: Marcel Dekker Inc.

Thompson, B. (1991). A premier on the logic and use of canonical correlation analysis.Measurement and Evaluation in counseling and Development, 24, 80-95. 